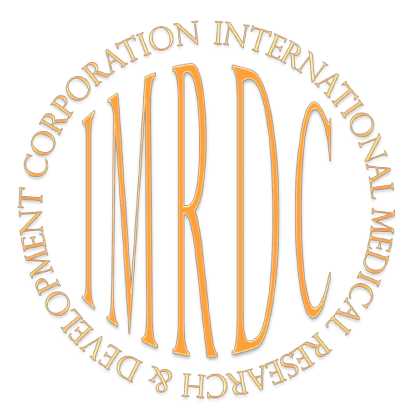

\title{
Lipid Profiles are Altered in Rats Fed with Different Garlic Cultivars
}

\author{
Ester Yoshie Yosino da Silva ${ }^{1}$, Celso Luiz Moretti ${ }^{2}$, \\ Leonora Mansur Mattos ${ }^{2 *}$ \\ ${ }^{I}$ College of Health Sciences, University of Brasilia, Brasilia, DF, Brazil \\ ${ }^{2}$ Embrapa, Parque Estação Biológica, Brasilia, DF, Brazil
}

\begin{abstract}
Garlic has antioxidant and hypocholesterolemic properties that are attributed to its organosulfur compounds being allicin, which is reported to be the most active of these compounds. We hypothesized that allicin content could reduce plasma concentrations of triglycerides (TG), total cholesterol (TC), HDL (high density lipoproteins), VLDL (very low density lipoproteins), and glucose. Two different cultivars of commercial garlic, Peruano and Jinxiang, were used. Thirty male Wistar rats were distributed into 6 groups and fed for 15 days with standard diet (Control), Control with Peruano garlic treatment (CGP), Control with Jinxiang garlic treatment $(\mathrm{CGCH})$, cholesterol-added control diet (CholC), cholesterol-added diet with Peruano garlic treatment (CholGP), and cholesterol-added diet with Jinxiang garlic treatment (CholGCH). Garlic treatment consisted of a daily oral dose of $1 \mathrm{ml}$ of lyophilized garlic. We observed that garlic treatment in Control group significantly reduced plasma TG and VLDL concentrations. The CGCH group presented a significant increase in plasma TC levels $(25.5 \%)$ and glucose (11\%). No significant changes in TC, HDL, TG and VLDL were observed in CholGP and CholGCH, but levels of fasting plasma glucose were increased: CholGP (23\%) and CholGCH (27.5\%). Results suggested allicin treatments alter lipid profile in rats. Nevertheless, further studies are necessary to address the increase in plasma glucose levels. (Int J Biomed. 2015;5(3):155-161.)
\end{abstract}

Keywords: powder garlic; allicin; rats; cholesterol; fasting plasma glucose.

\section{Abbreviations}

TC, total cholesterol; HDL, high density lipoprotein; VLDL, very low density lipoprotein; TG, triglycerides; Control, standard diet; CGP, Control with Peruano garlic treatment; CGCH, Control with Jinxiang garlic treatment; CholC, cholesterol added control diet; CholGP, cholesterol-added diet with Peruano garlic treatment; CholGCH, cholesterol-added diet with Jinxiang garlic treatment; OSC, organosulfur compound; CVD, cardiovascular disease.

\section{Introduction}

Garlic contains 33 organosulfur compounds (OSC), 17 amino acids (including all essential amino acids), minerals such as phosphorus, calcium, iron, potassium, magnesium, selenium, zinc, and vitamins $\mathrm{A}, \mathrm{B}, \mathrm{C}$, and $\mathrm{E}$ [1]. This bulb and its preparations have been widely recognized as an agent capable of preventing and treating cardiovascular diseases (CVD), atherosclerosis, thrombosis, hypertension, and diabetes $[2,3]$. It has been suggested that garlic's beneficial properties are attributed to specific OSC, including sulphoxides and

*Corresponding author: Leonora Mansur Mattos. Embrapa, Parque Estação Biológica, s/n, 70770-901, Brasilia, DF, Brazil. Email: leonora.mattos@embrapa.br $\gamma$-glutamil peptides that are present in the crude clove $[4,5]$.

Allicin (diallylthiosulfinate), a volatile liquid, is responsible for the pungent odor of garlic, representing approximately $70 \%$ of all thiosulfinates present in the crushed clove [6]. The compound is not found in intact plants, but it is formed by action of the enzyme named alliinase (EC4.4.1.4), derived from a non-proteinogenic amino acid $S$-allylcysteine $S$-oxide (aliin) at the time garlic is crushed [7]. In garlic powder the conversion of aliin to allicin begins when water is added to the powder, being quickly degraded into diallyl disulfide (DADS), vinyldithiins and ajoenes [8].

Atherosclerosis is one of the highest risk factor in hypertension development and CVD [9]. CVD are the main causes of death among the Western population. Risk of CVD is higher in men than in women who are in the pre-menopausal 
period. Multiple factors contribute to its development, such as lifestyle (smoking, physical inactivity, etc.) and stress. High levels of cholesterol in the plasma, particularly LDL and TG, are associated with an increase in CVD risk [10]. Oxidative change of LDL by reactive oxidative specie (ROS) is also considered an important mechanism in atherosclerosis and hypertension $[10,11]$. The cardio protector effect of garlic has been extensively assessed. Several in vitro studies have indicated that garlic and its components inhibit the key enzyme HMG-CoA reductase (3-hydroxi-3 methylglutaryl Coenzime $A$ ), which is associated with cholesterol and fatty acids synthesis [12-14]. In different assays carried out with animals, garlic extracts showed the ability to reduce cholesterol and lipid levels in the blood plasma of rats $[15,16]$. In humans, garlic significantly reduced plasma lipids levels, especially TC and LDL $[17,18]$. However, studies continue to be conducted due to the differences found. Active components of raw garlic may vary according to cultivar, harvest, and storage conditions. Various garlic preparations have been used in different studies. However, there is a lack in the literature concerning which are the most important active ingredients and how they impact lipid metabolism. Given this scenario, we hypothesized that the amount of allicin present in garlic could reduce the plasma concentration of TG, TC, HDL, VLDL, and glucose. To test our hypothesis we used an animal model and two commercial cultivars of garlic, Peruano and Jinxiang, grown in Brazil and China, respectively, which were submitted to a lyophilized process in order to preserve their properties and facilitate handling of the garlic throughout the experiment. This study aimed to: (a) assess the content of allicin in garlic cultivars (Peruano and Jinxiang), commercially available in the local market and (b) study the effect of allicin levels in reducing plasma concentrations of TG, TC, HDL, VLDL and plasma glucose in animals fed with either standard or cholesteroladded diets.

\section{Material and Methods}

\section{Garlic processing}

Bulbs of fresh garlic (Allium sativum L.), cultivar Peruano, were obtained from commercial and experimental fields in Brasília, DF, Brazil. Bulbs were harvested 150 days after planting and submitted to curing. Bulbs from Jinxiang cultivar, imported from China, were obtained at the local wholesale market. Fresh and healthy bulbs were selected and graded. Garlic cloves were manually stripped without harming the product, using a kitchen knife. Then they were frozen at a temperature of $-70 \pm 1{ }^{\circ} \mathrm{C}$ for approximately 8 hours, using an ultra-freezer (ULT1386-5-D40, Revco, Illinois, USA), sliced in an industrial processor (CL50, Robot Coupe, USA) with $5 \mathrm{~mm}$ thickness and immediately lyophilized (LS3000, Terroni, São Carlos, Brazil) for approximately 3 days. The product was then crushed in a knife mill (SL31, Solab, Piracicaba, Brazil), and put in sealed polyethylene bags.

\section{Allicin content determination}

Allicin content was determined according to the Institute for Nutraceutical Advancement 110.001 method INA [19]. Analyses were performed by a reversed phase, high-performance liquid chromatography (RP-HPLC) system (Shimadzu, Japan). Oven temperature was set at $28 \pm 0.5^{\circ} \mathrm{C}$. Samples were eluted with methanol and water $(50: 50 \mathrm{v} / \mathrm{v})$, using a flow of $1.0 \mathrm{~mL} / \mathrm{min}$ for 20 minutes and detected at $240 \mathrm{~nm}$. Injection volume was $25 \mu \mathrm{L}$. Allicin determination was performed comparing the area under the peak produced by the aqueous extract of garlic to a standard peak of allicin. Allicin standard solution was obtained by the oxidation of diallyl disulfide, according to Lawson \& Wang [20]. Allicin concentration $(\mathrm{C})$ in the solution was calculated according to Eq.:

$$
E_{10 m}^{1 \%}=\frac{A b s a r b a n c e}{C(\mu g / m L)} \times 10000 \text {, in which: }
$$

$E=$ extinction coefficient for allicin in water (145.4, considering a cell of $1 \mathrm{~cm}$ of wavelength of $240 \mathrm{~nm}$ ).

A standard curve was obtained by subsequent dilutions $(5,10,15,20,30,40,50,60,70$ and $80 \mu \mathrm{g} / \mathrm{mL})$ of the standard solution. To determine allicin content, lyophilized garlic powder was reconstituted with water. Samples of $0.4 \mathrm{~g}$ of garlic powder were placed in $50 \mathrm{~mL}$ plastic tubes, $10 \mathrm{~mL}$ of deionized water was added at room temperature and tubes were sealed using plastic film (Parafilm). Samples were homogenized using a tube agitator $\left(\mathrm{IKA}^{\circledR}\right.$, model MS1, German) and left at room temperature for approximately 6 minutes in order to produce OSC. Then samples were filtered through a filtrating membrane of $0.45 \mu \mathrm{m}$ (Millipore, USA) and transferred to an HPLC vial.

\section{Animals and diets}

The Institute of Biological Sciences/University of Brasilia (Brasilia, DF, Brazil), Ethical Committee for Animal Research approved all the adopted procedures (Protocol CEUA/ ICB/UnB no. 18914). Wistar male rats $(n=30)$ approximately 7 weeks old, used in the present study, were obtained from the Institute of Biological Sciences of University of Brasília. For 15 days, the animals were individually kept in polypropylene boxes in the following conditions: $23 \pm 2^{\circ} \mathrm{C}, 50 \%-60 \%$ relative humidity, and a photoperiod of 12 hours. All animals had free access to food and water. All experimental diets were distributed in a pellet form, based on the diet for growing rodents of the American Institute of Nutrition (AIN)-93G. After adaptation for one week, animals were randomly distributed in 6 groups of 5 animals each. Group 1 received the standard diet (Control). Groups 2 (CGP) and $3(\mathrm{CGCH})$ received the same diet as Group 1, with the addition of Peruano garlic (Group 2) and Jinxiang garlic (Group 3). Group 4 (CholC) received a cholesterol-based diet, containing $0.125 \%$ of sodium cholate and $0.5 \%$ of cholesterol (Control containing cholesterol), according to the model of Yanagita et al [21]. Groups 5 (CholGP) and 6 (CholGCH) received the same diet as Group 4, with Peruano garlic (Group 5) and Jinxiang garlic (Group 6) added (Table 1).

\subsection{Samples preparation for garlic treatment}

Lyophilized garlic powder was daily reconstituted with water and fed to the animals at the same time, in the morning, before the regular diet. The quantity was equivalent to 500 
mg of lyophilized garlic/kg of the animals' body mass [22]. Garlic powder was added with $1 \mathrm{~mL}$ of filtered water at room temperature, homogenized and left at the counter top for 6 minutes to yield OSC. Then rehydrated garlic was fed to animals by gavage. Each animal of every group (CGP, CGCH, CholGP and CholGCH) received $1 \mathrm{~mL}$ of reconstituted garlic and the other groups (Control and $\mathrm{CholC}$ ) received $1 \mathrm{~mL}$ of physiologic saline solution, once a day. During the experiment, garlic doses were adjusted according to the mass increase of the experimental animals.

Table 1.

Composition of experimental diets $(\mathrm{g} / \mathrm{Kg})$

\begin{tabular}{lcccc}
\hline \multicolumn{1}{c}{ Ingredients } & Control & $\begin{array}{c}\text { CGP/ } \\
\text { CGCH }\end{array}$ & CholC & $\begin{array}{c}\text { CholGP/ } \\
\text { CholCH }\end{array}$ \\
\hline Cornstarch $^{\dagger}$ & 529.49 & 524.49 & 523.24 & 518.24 \\
${\text { Casein }(\geq 85 \% \text { of protein })^{\dagger}}^{\dagger}$ & 200 & 200 & 200 & 200 \\
Sucrose $^{\ddagger}$ & 100 & 100 & 100 & 100 \\
L-cystine $^{\dagger}$ & 3 & 3 & 3 & 3 \\
Soybean oil $^{\S}$ & 70 & 70 & 70 & 70 \\
Microcrystalline cellulose $^{\dagger}$ & 50 & 50 & 50 & 50 \\
Mineral mixture - AIN93G $^{\dagger}$ & 35 & 35 & 35 & 35 \\
Vitamin mixture - AIN93G $^{\dagger}$ & 10 & 10 & 10 & 10 \\
Choline bitartrate $^{\dagger}$ & 2.5 & 2.5 & 2.5 & 2.5 \\
Tert-butylhydroquinone $^{£}$ & 0.014 & 0.014 & 0.04 & 0.014 \\
Cholesterol $^{£}$ & - & - & 5 & 5 \\
Sodium cholate $^{£}$ & - & - & 1.25 & 1.25 \\
Lyophilized garlic & - & 5 & - & 5 \\
\hline
\end{tabular}

Tested diets were formulated based on the diet AIN-93G.

${ }^{+}$Rhoster Indústria e Comércio Ltda (Vargem Grande Paulista, SP, Brazil).

* Vetec Química Fina (SP, Brazil).

$\S$ Refinações de Milho Brasil

${ }^{\ddagger}$ Sigma Chemical Co.(St Louis, MO, USA).

\section{Data collection}

Rats were daily monitored and individually weighed every 2 days and before blood collection at the end of the experiment. Their daily food ingestion and weight increments were registered during the experimental period.

\section{$\underline{\text { 5. Blood collection }}$}

Blood samples of each individual rat were collected at the end of the experiment with animals having fasted for 12 hours. Rats were anesthetized by the intraperitoneal route with quetamine association $(100 \mathrm{mg} / \mathrm{Kg})$ and xilazine $(10 \mathrm{mg} /$ $\mathrm{Kg}$ ). Blood collection was performed by cardiac punction. The animals' euthanasia was performed with an overdose of barbiturics. Blood was collected using sterilized syringes and needles and immediately transferred to dry hemolysis tubes with cap, stored in an ice bath, and taken for biochemical processing a maximum of 1 hour after collection. Plasma was separated using a centrifuge (SIGMA, 2-5, Osterode am Harz, Germany) at $1200 \mathrm{~g}$, for 10 minutes, at room temperature.

\section{Enzymatic analysis}

TC, HDL, TG and glucose were assessed using an enzymatic analytical kit from Abbott Laboratories (Illinois, USA) in automated equipment (ARCHITECT C8000, USA). VLDL fraction was calculated according to the following equation: $\quad \mathrm{VLDL}=($ Tryglicerides/5) used for triglyceride values $<400 \mathrm{mg} / \mathrm{dL}$ [23].

Statistical analysis: Results were expressed by mean \pm SD. Data were subjected to the chi-square test with $5 \%$ of probability, with the purpose of checking population adherence to the normal distribution curve. As there was no population adjustment to normal distribution, the non-parametric method of analysis using Kruskal Wallis test $(P<.05)$ was chosen.

\section{Results}

\section{Allicin content}

No significant differences in allicin content for fresh Peruano and Jinxiang garlics were observed. However, significant differences were verified when these varieties were lyophilized. The lyophilization process caused a significant reduction in allicin content for the Jinxiang cultivar (91\%) (Table 2).

Table 2.

Allicin content in the samples of aqueous extract of crude garlic and after lyophilization processing

\begin{tabular}{|l|c|c|c|}
\hline \multirow{2}{*}{ Cultivars } & \multicolumn{2}{|c|}{ Crude Garlic* } & Lyophilized garlic * \\
\cline { 2 - 4 } & mg/g FM product & $\mathrm{mg} /$ g DM product $^{*}$ & $\mathrm{mg} / \mathrm{g}$ DM product \\
\hline Peruano & $7.90 \pm 0.09^{\mathrm{a}}$ & $21.95 \pm 2.65^{\mathrm{a}}$ & $27.04 \pm 0.32^{\mathrm{a}}$ \\
Jinxiang & $6.73 \pm 0.03^{\mathrm{a}}$ & $20.04 \pm 0.49^{\mathrm{a}}$ & $1.88 \pm 0.26^{\mathrm{b}}$ \\
\hline
\end{tabular}

* a,b Means in the same column, followed by different letters, are statistically different among them at the level of $5 \%(P<0.05) . F M$ $=$ fresh matter and $D M=$ dry matter.

Jinxiang garlic was included in the present study once it was imported from China, and it was not possible to define all postharvest procedures until it reached the final market. On the other hand, Peruano garlic is grown locally and all the postharvest steps are known. These differences are probably associated with the observed distinct levels of allicin. Our study also showed that garlic variety influenced allicin during the lyophilization process.

\section{$\underline{\text { 2. In vivo experiment }}$}

Garlic treatment in the standard diets and cholesterolbased diets influenced the body weight of experimental animals (Table 3).

Table 3.

Effect of lyophilized powder garlic in standard diets and cholesterol added diets in relation to body weight, (g) weight gain (\%) and consumption of feed (g/day) in the rats groups

\begin{tabular}{llccl}
\hline $\begin{array}{l}\text { Study } \\
\text { Group }\end{array}$ & $\begin{array}{l}\text { Body weight } \\
1^{\text {st }} \text { day* }\end{array}$ & $\begin{array}{l}\text { Body weight } \\
15^{\text {th }} \text { day* }\end{array}$ & $\begin{array}{l}\text { Body } \\
\text { gain }\end{array}$ & $\begin{array}{l}\text { Feed } \\
\text { consumption }\end{array}$ \\
\hline Control & $184.17 \pm 12.36^{\mathrm{a}} 267.43 \pm 18.30^{\mathrm{a}} 45.34^{\mathrm{ba}}$ & $32.25 \pm 2.66^{\mathrm{ca}}$ \\
CGP & $172.17 \pm 12.09^{\mathrm{a}} 222.56 \pm 7.57^{\mathrm{b}}$ & $29.58^{\mathrm{b}}$ & $26.65 \pm 1.56^{\mathrm{dc}}$ \\
CGCH & $179.05 \pm 8.61^{\mathrm{a}} 264.14 \pm 15.09^{\mathrm{a}} 47.93^{\text {ba }}$ & $30.98 \pm 3.72^{\mathrm{ca}}$ \\
CholC & $177.66 \pm 3.17^{\text {a }}$ & $267.41 \pm 5.13^{\text {a }}$ & $50.53^{\text {ba }}$ & $33.22 \pm 2.15^{\mathrm{a}}$ \\
CholGP & $165.88 \pm 11.39^{\mathrm{a}} 218.46 \pm 6.19^{\mathrm{b}} 32.24^{\mathrm{b}}$ & $24.32 \pm 0.51^{\mathrm{db}}$ \\
CholGCH173.34 $\pm 8.06^{\mathrm{a}}$ & $284.84 \pm 10.34^{\mathrm{a}} 64.42^{\mathrm{a}}$ & $32.16 \pm 1.31^{\mathrm{a}}$ \\
\hline
\end{tabular}

Results expressed as mean $\pm S D$.

${ }^{b a}$ Different letters, in a same column, and in different assays, indicate a significant difference $(P<0.05)$. 
Rats that were treated with Peruano garlic (CGP and CholGP) showed lower body weight, lower increment in body weight after 15 days of study, and consumed lower amounts of feed compared to other groups. However, there were no statistical differences in body weight, weight increment, and feed consumption for the CholC group in relation to the Control group.

We verified similar trends in the CGP group, fed with $13.52 \mathrm{mg}$ of allicin $/ \mathrm{kg}$ of animal mass, to the study conducted by Elkayam et al [24]. Other studies conducted by Lee et al.[25] and Sohn et al. [9], both with diets enriched with garlic powder, did not show any change in food intake and in weight gain.

Our results showed that garlic can help in weight loss by reducing the appetite (Table 3 ). The possible mechanism of appetite reduction is probably associated with the strong odor of garlic, which stimulates the brain satiety center, reducing the desire to eat. It is still believed that garlic can stimulate the nervous system to release hormones such as adrenalin, which can accelerate the metabolic rate, helping in losing weight [26]. As Peruano garlic has higher amounts of allicin, it consequently has a more pungent odor, generating a stronger stimulus in the brain and, thus, accelerating metabolic rate.

Changes in lipid concentration in blood plasma after 15 days are shown in Figure 1. Group CGP kept cholesterol levels similar to the Control group, whereas the CholGCH group showed a significant increase $(25.5 \%)$. Rats fed with the cholesterol-based diet presented a significant increase in cholesterol levels in blood plasma when compared to the group fed with a standard diet. Groups CholGP and CholGCH did not present significant differences in relation to the CholC group.

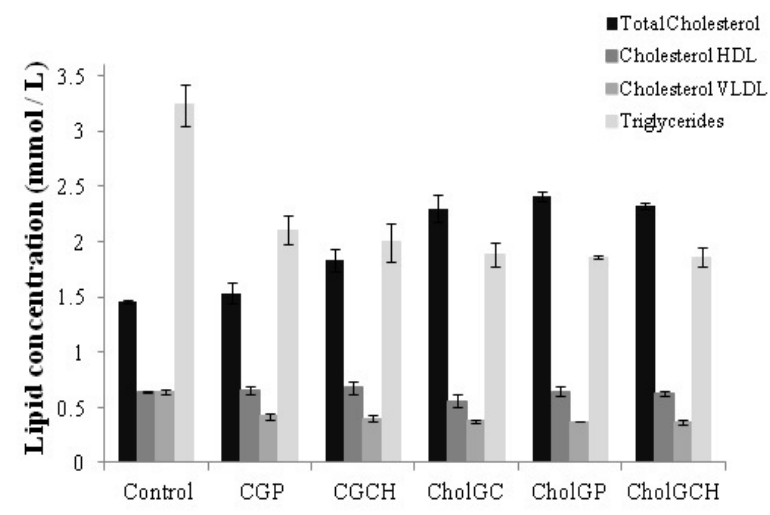

Fig. 1. Changes in lipid levels in blood plasma of rats fed with a diet either with or without cholesterol. Values are means. Vertical bars represent standard deviation.

Glucose levels in the plasma were altered due to different diets (Fig. 2). There was a significant increase in the CGCH group when compared to Control, as well as for CholGP and CholGCH when compared to CholC and Control. Therefore, in a standard diet, $\mathrm{CGCH}$ garlic consumption can increase the glucose level in the blood, as well as in CholGP and $\mathrm{CholGCH}$.

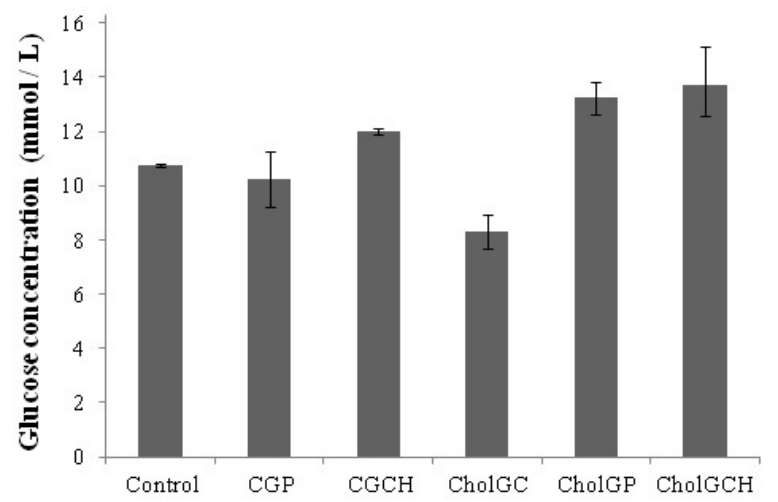

Fig. 2. Changes in glucose levels in blood plasma of rats fed with a diet either with or without cholesterol. Values are means. Vertical bars represent standard deviation.

\section{Discussion}

The observed difference is probably associated with allicin instability, which can vary during the process and with different cultivars [27,28]. Lawson and Hughes found 7.52 $\mathrm{mg} / \mathrm{g}$ of allicin in garlic powder, dried in slices with $3 \mathrm{~mm}$ thickness at $60^{\circ} \mathrm{C}$ for approximately 57 hours, followed by spraying using a mill. Garlic powder extract was obtained by adding water $(20 \mathrm{~mL} / \mathrm{g})$ and incubating at $23^{\circ} \mathrm{C}$ for 8 minutes, followed by filtration and evaluation with HPLC ( $240 \mathrm{~nm}$ and mobile phase of $50 \%$ of methanol in water). In the same study carried out by Lawson and Hughes [29], authors assessed the production of thiosulfinates during the garlic drying process. The amount of allicin formed in the fresh product was around $12.1 \mathrm{mg} / \mathrm{g}$ (dry weight) and the garlic powder was 11.6 $\mathrm{mg} / \mathrm{g}$ (dry weight). Loss caused by the drying procedure was nearly $4 \%$. In our study, we observed higher values either in fresh product or in garlic powder. According to Calín-Sánchez et al. [30], different drying methods can alter the final results, as one could expect. Garlic homogenization by spray-drier results in aliinase loss of activity, the same occurring with drying methods that use very high temperatures. Drying in low temperatures $\left(<60^{\circ} \mathrm{C}\right)$ has minor effects on the production of main thiosulfinates (allicin and alil methyl thiosulfinates). We also noticed that garlic cultivars influenced the activity loss of aliinase.

In another study, Lawson et al. [31] assessed different thiosulfinates, including allicin, present in tablets of garlic powder marketed in Australia, Germany, the USA and Japan. The amount found corresponded to $3.60 \mathrm{mg} / \mathrm{g}$ product (Australia); $3.10 \mathrm{mg} / \mathrm{g}$ product (USA); 0.26 to $2.55 \mathrm{mg} / \mathrm{g}$ product (Germany) and not detected (Japan). According to the authors, this wide range was due to different procedures used to prepare garlic powder, which has a potential to preserve the releasing capacity of allicin in garlic. However, while some garlic powders release a significant amount of allicin when in contact with water, many do not indicate any variation. Therefore, it is possible to observe variations in allicin content depending on garlic powder processing [32-34].

Future studies should address different processes to 
minimize allicin reduction during the drying process, searching for the best drying process for each cultivar, besides assessing possible formation of other organosulfur compounds and their effects in experimental animals.

Results of the present study associated with the CholGP group were similar to the ones observed in the investigation conducted by $\mathrm{Chi}$ at al. [35], in which rats fed with $1 \%$ of cholesterol, $15 \%$ of pig fat, and supplemented with $2 \%$ (320 $\mathrm{mg} /$ day) and $4 \%$ (640 mg/day) of garlic powder for 4 weeks, presented a significant reduction in feed ingestion and weight gain in the group with the cholesterol-based diet supplemented with $2 \%$ garlic.

Findings of the present investigation regarding cholesterol levels for the CGP group are in line with the results verified by Gorinstein et al. [21]. These researchers observed that rats fed with a standard diet supplemented with $25 \mathrm{mg}$ of lyophilized garlic powder, equivalent to $500 \mathrm{mg}$ of fresh garlic/kg of body weight, for 4 weeks did not present significant differences in relation to control. For the groups CholGP and CholGCH, our results were similar to the ones observed by Asdaq [36].

On the other hand, other studies verified results that are the opposite of ours. Aouadi et al. [37] observed that supplementing the standard diet with $10 \%$ fresh garlic (equivalent to $2 \%-3 \%$ of garlic powder) reduced plasma cholesterol in $12.2 \%$ of subjects. The study conducted by Ali et al.[38] showed a reduction of 35\% in plasma cholesterol in a high cholesterol diet (2\%) when rats were supplemented with $50 \mathrm{mg}$ of garlic powder $/ \mathrm{kg}$ animal weight, containing $0.6 \%$ of allicin. Chi et al. [35] verified a reduction in plasma cholesterol of $45.5 \%$ and $44 \%$ in rats fed with a diet containing $1 \%$ of cholesterol and supplemented with $2 \%$ and $4 \%$ of lyophilized garlic powder, respectively.

Although our data suggest an increase in HDL levels in the standard diets with garlic treatment, differences observed among treatments were not significant. Other studies verified similar results $[13,39]$.

There was a significant reduction in VLDL and TG serum concentrations for rats of groups $\mathrm{CGP}, \mathrm{CGCH}$, CholC, CholGP, and CholGCH when compared to Control. Reduction for the studied groups in both analyzed concentrations was: $35 \%$ for CGP, $38 \%$ for $\mathrm{CGCH}, 42 \%$ for CholC, CholGP and CholGCH. No significant differences were verified for VLDL and TG levels among the cholesterol-based diets. The present study showed that garlic treatments in a standard diet significantly reduced TG and VLDL concentrations in rats' plasma. Other studies showed a reduction in TG concentrations [40]. However, in general, many studies showed changes in TG and VLDL levels when standard diets, with moderate to high levels of cholesterol, were supplemented with garlic [41,29].

High levels of TG in the serum are associated with pathogenic conditions that accelerate atherosclerosis, such as insulin resistance and low levels of HDL [42]. Consequently, garlic consumption by groups $\mathrm{CGP}$ and $\mathrm{CGCH}$ can reduce the risk of cardiovascular diseases due to the reduction of TG and VLDL levels.

The effect of garlic in glucose concentrations was not addressed significantly in the searched literature, and the studies carried out had inconsistent results. Chi et al. [35] and Seo et al. [43] showed a significant reduction in glucose levels in rats fed with a high content cholesterol diet supplemented with garlic powder.

Thomson et al. [40] showed in a study that aqueous extract of fresh garlic ingested in small quantities $(50 \mathrm{mg} /$ $\mathrm{kg}$ ) reduces the concentration of cholesterol and triglyceride and does not alter the glucose level in the plasma. However, the study found that high doses of garlic $(500 \mathrm{mg} / \mathrm{kg}$ ) would reduce plasma glucose levels, which is different from the results verified in this study.

The effect of garlic, and especially allicin, on the lipid profile has been the object of many controversies in animal models, since there is no standardization for the garlic concentration used. There are papers that have mentioned the protective effect to health of fresh garlic but not allicin, since they use garlic as the study base. There are several methods of preparing garlic and, specifically for garlic powder, there are several ways to process it, which implies variation in allicin content. The duration of the experiment duration is also questionable; many studies already published have shown different assessment times. Garlic cultivars present variable results in vitro which can generate differences in the in vivo results. All these facts, among others not mentioned, can explain the differences presented in our study regarding the literature data on TC, HDL, VLDL, TG and glucose levels in the plasma of experimented animals.

Concerning garlic ingestion, a significant part of the worldwide population consumes garlic as a condiment in their usual meal, without a defined quantity. The effective dose of garlic has not been determined; however, clinical studies in humans have shown that the ingestion of 4 to $6 \mathrm{~g}$ of garlic powder/day is considered safe when done in a meal [44]. Our results are within the range of these values, after extrapolation of the animal dose of $500 \mathrm{mg}$ of garlic powder $/ \mathrm{kg}$ of the animal weight. This amount corresponds to $4.86 \mathrm{~g}$ of garlic powder for one person with $60 \mathrm{~kg}$, according to the Food and Drug Administration [45].

\section{Conclusions}

The present study showed differences in allicin content between two garlic cultivars assessed after a lyophilization process. We also observed differences in the in vivo results, probably due to the differences verified for allicin content. The ingestion of Peruano garlic reduced TG and VLDL levels in blood plasma of animals fed with a standard diet. These results indicate that this cultivar might have an important role in the prevention of atherosclerosis. On the other hand, although Jinxiang garlic consumption reduced TG and VLDL levels, it increased TC levels in $25.5 \%$ of the animals kept on a standard diet and increased glucose levels $12 \%$ and $27.5 \%$ in those on standard diets and cholesterol-based diets, respectively. Thus, this cultivar can present a risk factor for diabetes and it is not recommended to be used as a lyophilized product, in the conditions under which the present study was carried out. Our work is, to the best of our knowledge, the first to show 
that garlic powder can significantly affect the levels of plasma glucose. Thus, it should be monitored periodically to identify, in future studies, possible mechanisms associated with this increment. For consumption of fresh garlic, additional studies should focus on how these cultivars can contribute to the reduction of the parameters (CT, LDL, VLDL and TG) associated with CVD.

\section{Competing interests}

The authors declare that they have no competing interests.

\section{Acknowledgments}

We would like to thank the financial support of Embrapa and the Coordenação de Aperfeiçoamento de Pessoal de Nível Superior - CAPES (Brazil) for providing funding and the scholarship, respectively, for this research.

\section{References}

1. Omar SH, Al-Wabel NA. Organosulfur compounds and possible mechanism of garlic in cancer. Saudi Pharm J. 2010; 18(1):51-58.

2. Agarwall KC. Therapeutic actions of garlic constituents. Med Res Rev. 1996; 16(1):111-24.

3. Khatua TN, Adela R, Banerjee SK. Garlic and cardioprotection: insights into the molecular mechanisms 1 . Can J Physiol Pharm. 2013; 91(6): 448-58.

4. Bayan L, Koulivand PH, Gorji A. Garlic: a review of potential therapeutic effects. Avicenna J Phytomed. 2014; 4(1):1-14.

5. Fei ML, Tong LI, Wei LI, De Yang L. Changes in antioxidant capacity, levels of soluble sugar, total polyphenol, organosulfur compound and constituents in garlic clove during storage. Ind Crop Prod. 2015; 69:137-42.

6. Borlinghaus J, Albrecht F, Gruhlke MC, Nwachukwu ID, Slusarenko AJ. Allicin: Chemistry and biological properties. Molecules. 2014; 19(8):12591-618.

7. Iciek M, Kwiecień I, Chwatko G, Sokołowska-Jeżewicz M, Kowalczyk-Pachel D, Rokita H. The effects of garlicderived sulfur compounds on cell proliferation, caspase 3 activity, thiol levels and anaerobic sulfur metabolism in human hepatoblastoma HepG2 cells. Cell Biochem Funct. 2012; 30(3):198-04.

8. Kay HY, Yang JW, Kim TH, Kang B, Ryu JH, Jeon R, et al. Ajoene, a stable garlic by-product, has an antioxidant effect through Nrf2-mediated glutamate-cysteine ligase induction in HepG2 cells and primary hepatocytes. J Nutr. 2010; 140(7):1211-19.

9. Sohn CW, Kim H, You BR, Kim MJ, Kim HJ, Lee JY, et al. High temperature-and high pressure-processed garlic improves lipid profiles in rats fed high cholesterol diets. Journal of Medicinal Food. 2012; 15(5):435-40.

10. Chen K, Keaney Jr JF. Evolving concepts of oxidative stress and reactive oxygen species in cardiovascular disease. Curr Atheroscler Rep. 2012; 14(5):476-83.

11. Rahman K, Lowe GM. Garlic and cardiovascular disease: a critical review. J Nutr. 2006; 136(3): 736S-40S.

12. Ried K, Toben C, Fakler P.). Effect of garlic on serum lipids: an updated meta-analysis. Nutr Res. 2013; 71(5): 282-99. 13. Yun HM, Ban JO, Park KR, Lee CK, Jeong HS, Han
SB, et al. Potential therapeutic effects of functionally active compounds isolated from garlic. Pharmacol Therapeut. 2014; 142(2): 183-95.

14. Zeng T, Zhang CL, Song FY, Zhao XL, Xie KQ. Garlic oil alleviated ethanol-induced fat accumulation via modulation of SREBP-1, PPAR- $\alpha$, and CYP2E1. Food Chem Toxicol. 2012; 50(3): 485-91.

15. Heidarian E, Jafari-Dehkordi E, Seidkhani-Nahal A. Effect of garlic on liver phosphatidate phosphohydrolase and plasma lipid levels in hyperlipidemic rats. Food Chem Toxicol. 2011; 49(5): 1110-14.

16. Tsai CW, Chen HW, Sheen LY, Lii CK. Garlic: Health benefits and actions. BioMedicine. 2012; 2(1): 17-29.

17. Koseoglu M, Isleten F, Atay A, Kaplan YC. (2010). Effects of acute and subacute garlic supplement administration on serum total antioxidant capacity and lipid parameters in healthy volunteers. Phytother Res. 2010:24(3): 374-78.

18. Sobenin IA, Pryanishnikov VV, Kunnova LM, Rabinovich YA, Martirosyan DM, Orekhov AN. The effects of time-released garlic powder tablets on multifunctional cardiovascular risk in patients with coronary artery disease. Lipids Health Dis. 2010; 9: 119.

19. INA (2005). Allicin Content in Garlic by HPLC (INA method 110.001). NSF International. Allicin by highperformance liquid chromatography. (INA Method 110.001). Retrieved from http://www.nsf.org/business/ina/garlic.asp. 20. Lawson LD, Wang ZJ. Low allicin release from garlic supplements: a major problem due to the sensitivities of alliinase activity. J Agr Food Chem. 2001;49(5):2592-99.

21. Yanagita T, Han SY, Wang YM, Tsuruta Y, Anno T. Cycloalliin, a cyclic sulfur imino acid, reduces serum triacylglycerol in rats. Nutrition. 2003;19(2): 140-143.

22. Gorinstein S, Jastrzebski Z, Namiesnik J, Leontowicz H, Leontowicz M, Trakhtenberg S. The atherosclerotic heart disease and protecting properties of garlic: contemporary data. Mol Nutr Food Res. 2007; 51(11): 1365-81.

23. Friedewald WT, Levy RI, Fredrickson DS. Estimation of the concentration of low-density lipoprotein cholesterol in plasma, without use of the preparative ultracentrifuge. Clin Chem.1972; 18(6):499-02.

24. Elkayam A, Peleg E, Grossman E, Shabtay Z, Sharabi Y. (2013). Effects of allicin on cardiovascular risk factors in spontaneously hypertensive rats. Isr Med Assoc J. 2013; 15(3):170-3.

25. Lee S, Joo H, Kim CT, Kim IH, Kim Y. High hydrostatic pressure extract of garlic increases the HDL cholesterol level via up-regulation of apolipoprotein AI gene expression in rats fed a high-fat diet. Lipids Health Dis. 2012; 11(77):1-7.

26. Daniels JB. Lose weight in record time with the fast metabolism diet: how certain foods can help you to shed those extra pounds. Speedy Publishing LLC; 2013.

27. Bloem E, Schroetter S, El-Khayat ASM, Schnug E. Influence of sulphur and nitrogen supply on the pigment content of oilseed rape, marigold, and beetroot. Phyton. 2011; 50(2):301-17.

28. Lee J, Gupta S, Huang JS, Jayathilaka LP, Lee BS. HPLCMTT assay: Anticancer activity of aqueous garlic extract is from allicin. Anal Biochem. 2013; 436(2):187-9.

29. Lawson LD, Hughes BG. Characterization of the formation of allicin and other thiosulfinates from garlic. Planta Med.1992; 58(4):345-50.

30. Calín-Sánchez Á, Figiel A, Wojdyło A, Szarycz M, Carbonell-Barrachina ÁA. Drying of garlic slices using 
convective pre-drying and vacuum-microwave finishing drying: kinetics, energy consumption, and quality studies. Food Bioprocess Tech. 2014; 7(2):398-408.

31. Lawson LD, Wang ZYJ, Hughes BG. $\gamma$-Glutamyl-Salkylcysteines in garlic and other Allium spp.: Precursors of age-dependent trans-1-propenyl thiosulfinates. J Nat Prod. 1991; 54(2):436-44.

32. Cavagnaro PF, Galmarini CR. Effect of processing and cooking conditions on onion (Allium cepa L.) induced antiplatelet activity and thiosulfinate content. J Agr Food Chem. 2012; 60(35):8731-37.

33. Chen S, Shen X, Cheng S, Li P, Du J, Chang Y, et al. Evaluation of garlic cultivars for polyphenolic content and antioxidant properties. PloS One. 2013; 8(11):e79730.

34. Nazari B. Comparison of the Effect of Different Levels of Garlic Powder on the Levels of Serum Cholesterol and Triglyceride of Two Strains Broiler Chicks (Arian and Ross). Qom University of Medical Sciences Journal. 2012; 2(3). 35. Chi MS, Koh ET, Stewart TJ. (1982). Effects of garlic on lipid metabolism in rats fed cholesterol or lard. J Nutr. 1982; 112(2): 241-8.

36. Asdaq SMB. Antioxidant and Hypolipidemic Potential of Aged Garlic Extract and Its Constituent, S-Allyl Cysteine, in Rats. J Evid Based Complementary Altern Med. 2015; 1:1-7. 37. Aouadi R, Aouidet A, Elkadhi A, Rayana MCB, Jaafoura $\mathrm{H}$, Tritar B, et al. Effect of fresh garlic (Allium sativum) on lipid metabolism in male rats. Nutr Res. 2000; 20(2):273-80. 38. Ali M, Al-Qattan KK, Al-Enezi F, Khanafer RMA, Mustafa T. Effect of allicin from garlic powder on serum lipids and blood pressure in rats fed with a high cholesterol diet. Prostag Leukotr Ess. 2000; 62(4):253-259.

39. Santhosha SG, Jamuna P, Prabhavathi SN. Bioactive components of garlic and their physiological role in health maintenance: A review. Food Bioscience. 2013; 3:59-74.

40. Thomson M, Al-Qattan KK, Bordia T, Ali M. Including garlic in the diet may help lower blood glucose, cholesterol, and triglycerides. J Nutr. 2006; 136(3):800S-02S.

41. Jung ES, Park SH, Choi EK, Ryu BH, Park BH, Kim DS, et al. Reduction of blood lipid parameters by a 12 -week supplementation of aged black garlic: a randomized controlled trial. Nutrition. 2014; 30(9):1034-1039.

42. Chapman MJ, Ginsberg HN, Amarenco P, Andreotti F, Borén J, Catapano AL, et al. Triglyceride-rich lipoproteins and high-density lipoprotein cholesterol in patients at high risk of cardiovascular disease: evidence and guidance for management. Eur Heart J. 2011; 32(11):1345-61.

43. Seo YJ, Gweon OC, Im J, Lee YM, Kang MJ, Kim JI. Effect of garlic and aged black garlic on hyperglycemia and dyslipidemia in animal model of type 2 diabetes mellitus. Journal of Food Science and Nutrition. 2009;14(1):1-7. 44. Eilat-Adar S, Sinai T, Yosefy C, Henkin Y. Nutritional recommendations for cardiovascular disease prevention. Nutrients. 2013; 5(9):3646-3683.

45. USFDA (2002). Estimating the safe starting dose in clinical trials for therapeutics in adult healthy volunteers. Center for Drug Evaluation and Research, Food and Drug Administration, U.S. Department of Health and Human Services. 